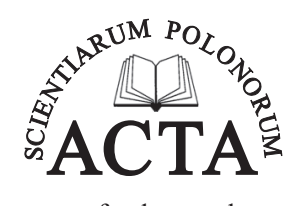

www.food.actapol.net

Acta Sci. Pol. Technol. Aliment. 15(1) 2016, 47-56

pISSN 1644-0730

eISSN 1889-9594

DOI: 10.17306/J.AFS.2016.1.5

ORIGINAL PAPER

Received: 18.10.2015

Accepted: 28.12.2015

\title{
TAPIOCA MALTODEXTRIN IN THE PRODUCTION OF SOFT UNRIPENED CHEESE*
}

\author{
Natalia V. lakovchenko ${ }^{\bowtie}$, Tamara P. Arseneva \\ Department of Applied Biotechnology, Faculty of Food Biotechnology, ITMO University \\ Lomonosova 9, 191002, Saint-Petersburg, Russia
}

\begin{abstract}
Background. An excessive consumption of fat has been associated with an increased risk of health problems such as obesity, diabetes and cardiovascular diseases. Cheese is a highly concentrated product which is rich in protein and minerals such as calcium and phosphorus and essential amino acids, therefore it is an important food in the diet. But low fat cheeses are usually characterized as having poor body and flavour. Therefore, it is crucial to find ways of improving the acceptability of the product. The aim of this research was to investigate the possibility of using of tapioca maltodextrin in the production of soft cheese made from ultrafiltrated skimmed milk and to create organoleptic properties of a fat product in a non-fat product.

Material and methods. To estimate the possibility of using tapioca maltodextrin in the production of soft cheese, the influence of tapioca maltodextrin on rennet flocculation time (RFT) and rennet clotting time (RCT), $\mathrm{pH}$ values, moisture content were estimated. Improving the quality of cheese, rheological and sensory characteristics in the course of soft unripened cheese manufacturing has to be focused on.

Results. Using tapioca maltodextrin led to decrease in RFT and RCT. The concentration increase of the maltodextrin in milk for cheese production led to increase in moisture-binding capacity and moisture content of the cheeses, but led to decrease in RFT, RCT and pH-value. Based on the experiments data the optimal doses of tapioca maltodextrin were recommended.

Conclusions. An addition of tapioca maltodextrin resulted in a tendency of decreasing RFT and RCT, $\mathrm{pH}-$ -value for cheese made with different concentrations of tapioca maltodextrin when compared to cheese made without maltodextrin addition. At the same time an increased amount of tapioca maltodextrin led to moisture content increase of cheese samples. Inclusion of tapioca maltodextrin in natural, low fat cheese may improve texture and acceptability as compared to low fat control cheeses without maltodextrin. The recommended level of tapioca maltodextrin is $1.1 \%$ of the mixture weight.
\end{abstract}

Key words: ultrafiltration, soft cheese, tapioca maltodextrin, non-fat cheese

\section{ABBREVIATION KEY}

RCT rennet clotting time

RFT rennet flocculation time

SM skimmed milk
UFC ultrafiltration concentrate of skimmed milk

UFT Multrafiltration concentrate of skimmed milk with tapioca maltodextrin

\footnotetext{
${ }^{*}$ This work was partially financially supported by Government of Russian Federation, Grant 074-U01.

凶rack@mail.ru
} 


\section{INTRODUCTION}

Cheese is an excellent source of protein and minerals such as calcium and phosphorus, essential amino acids, therefore it is an important food product for both young and old people (Krupa et al., 2011).

The protein concentration of milk varies according to the season, weather, feed type, stage of lactation, breed of lactating cows and health status of the animal (the incidence of mastitis, for instance; Paul Kindstedt, 2005). This variation has a major influence on the production of cheese (Ong et al., 2013). Ultrafiltration can help minimize seasonal variations in milk composition, which, in turn, can help standardize rennet coagulation time, gel strength, and cheese yield (Lucey, 2000).

Ultrafiltration is a variety of membrane filtration which allows to concentrate and separate molecules in solution based on differences in molecular weight in conjunction with membrane molecular cut-off weight. Physical separation by membrane filtration of skim milk gives two liquids: the ultrafiltrate or permeate and the retentate. Casein and all true whey proteins are retained in the ultrafiltration retentate of milk, whereas the non-protein nitrogen, lactose, minerals, which are not bound with the protein, are partly lost to the ultrafiltration permeate. Moreover, ultrafiltration is one way of removing some of the water from milk before making cheese, allowing to fill more cheese fats during the day (Erdem, 2000; Fetisov and Chagorovskij, 1991; Grandison and Glover, 1997; Outinen, 2010).

Obesity, diabetes, high blood pressure, cardiovascular system disorders, atherosclerosis have a considerable impact on the population through their high influence on mortality and quality of life (WHO). Nowadays, the awareness of the consumer of dietary aspects of food in relation to these diseases has increased. That makes the extension range of low fat or non-fat products an actual problem. One way of solving it is addition of fruit or vegetable supplements to non-fat food products, as for instance, lupin protein concentrate to create a combined non-fat yoghurt (Kuznetsova et al., 2014). Another way is to create products using fat-replacers, which not increase the calorie content, but improve the sensory characteristics of finished products.

The acceptability of cheese depends on its appearance and sensory properties. Fat plays an important role in cheese of imparting discontinuity to the protein matrix, so when fat is removed the cheese is composed of a homogenous, dense protein network (Paulson et al., 1998). Since reduced-fat cheeses, especially fat-free cheeses are less acceptable to consumers than their full-fat counterparts due to their poor texture and dilute flavour, it is desirable to provide a non-fat soft cheese which emulates the organoleptic properties of soft cheese which contains substantial levels of milk fat. For this reason, fat replacer compounds are used to fully or partially replace fat in reduced-fat foods (Drake et al., 1996). Fat mimetics, which are carbohydrate- or protein-based, imitate organoleptic or physical properties of triglycerides and generally adsorb a substantial amount of water (Akoh, 1998).

Many studies were focused on reducing calorie content of cheese and improving its textural and organoleptic properties. Sipahioglu et al. (1999) used modified tapioca starch and lecithin, as fat mimetics, to obtain reduced fat and low-fat feta cheeses. In addition, different protein-based and carbohydrate-based fat replacers were used to obtain low-fat cheeses and their textural and sensory properties have been studied (Kavas et al., 2004; Koca and Metin, 2004; Zalazar et al., 2002).

Pagliarini and Beatrice (1994) have reported the use of inulin, a vegetable fibre as fat replacers in the manufacture of low-fat cheese. Studies carried out by Bhaskaracharya (2004) on skimmed milk mozzarella cheese made using maltodextrin and mixture of $\beta$-lactoglobulin, carageenan and xanthan gum. Hennelly et al. (2006), Koca and Metin (2004), Pagliarini and Beatrice (1994) showed that the addition of long-chain inulin to low-fat cheese resulted in enhanced creaminess.

In the study the main requirements for the component selection were as follows: it should be permitted for use in food industry, the component should be safe for the human body, the use of additive should not significantly complicate the product manufacturing process and increase the duration of its cycle to high extent. Usually maltodextrin is a moderately sweet polysaccharide. Therefore, as it generally used as food additives, the slightest amount of flavour or taste may create a problem. Since tapioca maltodextrin has no flavour or is nearly tasteless it was chosen in the research.

Maltodextrin is an intermediate-length polymer obtained from starch using natural enzymatic process. Maltodextrins simulate the taste of fat and offer less 
calories per gram than 9 calories per gram in fat (Vaclavik and Christian, 2008).

The objective of this research was to develop a composition of soft cheese made from ultrafiltrated skimmed milk and to determine the influence of tapioca maltodextrin on organoleptic, physicochemical properties of the product.

\section{MATERIAL AND METHODS}

Whole raw cow milk (3.1\% of fat) was obtained from the local farmer's market. Prior to ultrafiltration it was subjected to separation at a temperature of $40^{\circ} \mathrm{C}$, heated to $65^{\circ} \mathrm{C}$ and held at that temperature during $25 \mathrm{~s}$. The thermization allows to reduce the total bacterial content of milk, that is, it contributes to the destruction of psychrotrophic microorganisms, thus eliminating the formation of enzymes which are resistant to pasteurization (Fetisov and Chagorovskij, 1991).

Milk was concentrated in a laboratory scale unit Vivaflow 50 ('Vivascience', Sartorius group). The system contains polyethersulfone membranes with molecular cut-off weight of $30 \mathrm{kDa}$. Skimmed milk (SM) was ultrafiltrated at a temperature $50^{\circ} \mathrm{C}$ until a retentate with concentration factor of 2 was obtained. Comparison of important physicochemical aspects of SM and ultrafiltration concentrate of skimmed milk (UFC) is given in Table 1.

Table 1. Composition of skimmed milk and ultrafiltrated skimmed milk

\begin{tabular}{lcc}
\hline \multicolumn{1}{c}{ Component } & SM & UFC \\
\hline Protein content, \% & $3.06 \pm 0.15$ & $6.1 \pm 0.08$ \\
Fat content, \% & $0.08 \pm 0.01$ & $0.17 \pm 0.01$ \\
Solids non-fat, \% & $8.62 \pm 0.15$ & $12.0 \pm 0.15$ \\
Lactose content, \% & $4.75 \pm 0.2$ & $4.9 \pm 0.2$ \\
Ash,\% & $0.78 \pm 0.1$ & $0.83 \pm 0.1$ \\
pH & $6.71 \pm 0.04$ & $6.61 \pm 0.04$ \\
\hline
\end{tabular}

Each value is calculated as average of five replicates.

BC-Uglich-4 (Lactococcuslactis subsp. lactis, Lactococcuslactis subsp. cremoris, Lactococcuslactis

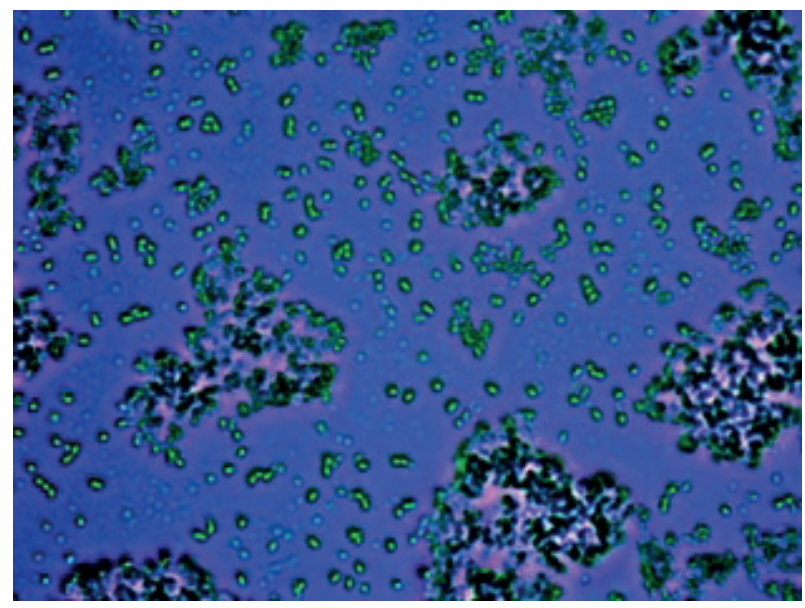

Fig. 1. Microscopic slide of starter culture $(630 \times$ magnification)

subsp. diacetilactis, Leuconostoclactis) used as a starter culture was obtained from Uglich Experimental Biofactory, Russia. Microscopic slide was viewed in a digital Carl Zeiss AxioLab A1 Microscope, see Figure 1.

Calf rennet was obtained from Moscow factory of rennet, Russia. Pregelatinized tapioca maltodextrin with commercial name N-DULGE CA1 was obtained from "Ingredion UK Limited".

Solids-non-fat, fat of SM and UFC were measured using milk analyzer «Klever-2». Total protein of SM was measured by «Klever-2». Total proteinof UFC was measured by Kjeldahl Method according to AOAC method 991.20 (2000). Lactose content in SM and UFC was measured according to iodometric method (Ohrimenko et al., 2005). Ash content was determined by gravimetric method using a muffle furnace according to AOAC method 945.46 (1995). $\mathrm{pH}$ values were measured using $\mathrm{pH}-$ meter $(\mathrm{pH}-410$ with a glass combination electrode), Russia. Moisture content of cheese samples were analyzed according to AOAC method 948.12 (2002).

Determination the influence of maltodextrin concentration on rennet flocculation time (RFT) and rennet clotting time (RCT). Samples of SM, UFC and UFC with concentrations of matodextrin from $0.5 \%(\mathrm{w} / \mathrm{v})$ to $2 \%(\mathrm{w} / \mathrm{v})$ with the increment of $0.5 \%$ $(\mathrm{w} / \mathrm{v})$ were prepared. 
To define RFT method as according to Sommer and Matsen (1935) was used. Samples pasteurized at $74 \pm 2^{\circ} \mathrm{C}$ for $20-25 \mathrm{~s}$ and cooled to $30^{\circ} \mathrm{C}$. Prepared diluted rennet enzyme solution $(2 \%(\mathrm{v} / \mathrm{w}))$ was added in bottles with milk samples. During the experiment bottles were rotated slowly in a water bath at controlled temperature until the first sign of flocculation was observed and the time of flocculation was recorded. RFC is time from addition of the rennet to the first formation of initial visible floccules of casein on the glass wall of a test bottle. The end of RCT was defined as the point at which the curd is firm enough to be cut during cheese making. It was determined with sensory evaluation by inserting the spatula into coagulum at 45-degree angle, gently lifting the spatula and observing the curd split. A sharp, clean split indicates that the curd is ready for cutting. The experiment was repeated in triplicate using one batch of milk. Data obtained are presented in Table 4.

\section{Determination the influence of maltodextrin con-} centration on moisture-binding capacity of cheese

curds. Set of cheese rennet curds samples made from UFC with concentrations of tapioca matodextrin varied from $0.5 \%(\mathrm{w} / \mathrm{v})$ to $2 \%(\mathrm{w} / \mathrm{v})$ with the increment of $0.5 \%(\mathrm{w} / \mathrm{v})$ were prepared. The amount of calf rennet added to each sample was equal. The moisture-binding capacity was estimated visually and by the amount of separated whey during the centrifugation. Cheese rennet curds were stirred and $10 \mathrm{~g}$ of each sample was weight into centrifuge tubes. The tubes were centrifuged and the amount of separated whey was measured every $5 \mathrm{~min}$ during $30 \mathrm{~min}$. The separated from the curd whey (Fig. 2) was denoted as expressible whey. The experiment was repeated in triplicate using one batch of milk.

Evaluation of cheese sample consistency was studied using digital penetrometer Koehler K95500. This method is based on the principle of penetrating the test material with a cone-shaped metal probe for $5 \mathrm{sec}$ and measuring the depth of cone penetration. Three penetration tests for each cheese sample were done using $60^{\circ}$ aluminum cone. Three penetration tests for each cheese sample were done. The results of penetrometer measurements were converted according to the formula:

$$
S_{0}=\frac{K_{1} m g}{p^{n}}
$$

where:

$S_{0}$ - yield value, $\mathrm{g} / \mathrm{cm}^{2}$,

$p$ - depth of penetration, $\mathrm{cm}$,

$m$ - the weight of the cone plus mobile parts, $\mathrm{g}$,

$g-$ acceleration due to gravity $=9.81 \mathrm{~m} \cdot \mathrm{s}^{-2}$,

$n-$ a constant with a value depending on the properties of the sample being tested, and approximating to 2 (Rebinder and Semenenko, 1949).

$$
K_{1}=\frac{1}{\pi} \cos ^{2} \alpha \cdot \cot \alpha=\text { cone constant }
$$

where: $\alpha$ - half of the cone angle.

Soft cheeses were classified according to Table 2 (Haighton, 1959).

Table 2. Textural classification of materials according to Yield Stress

\begin{tabular}{cl}
\hline $\begin{array}{c}\text { Yield value } \\
\mathrm{g} / \mathrm{cm}^{2}\end{array}$ & \multicolumn{1}{c}{ Assessment } \\
\hline$<50$ & very soft to just pourable \\
$50-100$ & very soft, not spreadable \\
$100-200$ & soft, but already spreadable \\
$200-800$ & plastic and spreadable \\
$800-1000$ & hard, but satisfactory spreadable \\
$1000-1500$ & too hard, limit of spreadability \\
$>1500$ & too hard \\
\hline
\end{tabular}

Manufacturing of soft cheese. Based on the fact that whey proteins can be used as protein-based fat replacement it was determined that ultrafiltration allows to some extent to improve sensory properties of soft cheese made from skim milk. But it had a little effect on getting soft cheese with the appearance, taste, consistency and texture of cheese made from the whole milk.

Blending whey protein with carbohydrates is another way to improve organoleptic properties of soft cheese.

To determine concentrations of tapioca maltodextrin, acceptable for cheese manufacture, retentate with a target protein concentration of $6 \%$, was divided 
into several parts. As a control sample cheese made from SM was chosen and was produced via traditional industrial technology of soft unripened cheese as follows: $\mathrm{SM}$ was heated at $74 \pm 2{ }^{\circ} \mathrm{C}$ for $20-25 \mathrm{~s}$ and cooled to $30^{\circ} \mathrm{C}$. $\mathrm{CaCl}_{2}(30 \mathrm{~g}$ of anhydrous salt for each $100 \mathrm{~kg}$ of milk) as a $40 \%$ solution was added. Starter culture prepared by inoculating sterilized SM with culture was added in the amount of $1 \%$. During the fermentation of starter culture, lactic acid accumulates, which causes the $\mathrm{pH}$-value to decrease, resulting in better whey drainage. The SM was coagulated with calf rennet $(1 \%$ solution $(\mathrm{w} / \mathrm{v}))$ in the amount providing milk coagulation in $60 \mathrm{~min}$ and left to curdle.

After the coagulation, the curds were cut into small equal cubes with vertical and horizontal curd knifes which were gently stirred for $5 \mathrm{~min}$, left undisturbed for $10 \mathrm{~min}$. Then, $30 \%$ of free whey was drained out and the curd stirred for $15 \mathrm{~min}$. After that the curd was transferred into special perforated rectangular moulds for draining and pressed under the force of gravity. The samples of cheese were turned upside-down three times during the first $5 \mathrm{~h}$ of draining and pressing at $16-18^{\circ} \mathrm{C}$. Then the cheeses were soaked in a concentrated brine solution (18-22\%) for salting.

The UFC was divided into several parts using 11 for each sample: sample made from UFC without maltodextrin and samples with different concentrations of maltodextrin. The doses of the tapioca maltodextrin ranged from $0.3 \%$ to $1.3 \%$ of retentate weight with the increment of $0.2 \%$. The concentration range was chosen according to the manufacturer's recommendations.

During the process of studying the possibility of using tapioca maltodextrin, the technology of production of cheese was changed to some extent in comparison with the conventional soft cheese technology:

- to provide uniform distribution of the supplement in the total volume of the mixture and incorporate it into the cheese curd, maltodextrin was premixed with a small amount of retentate and then added to the UFC prior to heat treatment at $74 \pm 2^{\circ} \mathrm{C}$ for $20-25 \mathrm{~s}$

- during the manufacture the removal of free whey was excluded.

All other steps of cheese production were according to the technology of soft cheese made from SM.

Sensory evaluation was performed the next day after pressing under force of gravity, salting and storage at $5 \pm 1{ }^{\circ} \mathrm{C}$. Samples of cheeses were evaluated for organoleptic properties by a sensory panel consisting of 12 staff members and students of the Department of Applied Biotechnology. The participants were selected and trained in accordance with the ISO 8586-1 standard (1993). In sensory evaluation, 50\% of participants were female from 20 to 65 years old and 50\% of participants were male from 19 to 58 years old. Requirements for the work of the group of assessors were according to ISO 8589 standard (2007). Cheese samples were labelled with random three-digit codes and

Table 3. Description of organoleptic features for several sensory features, used by selected assessors to assess soft cheeses

\begin{tabular}{|c|c|c|c|}
\hline \multirow{2}{*}{ Sensory features } & \multirow{2}{*}{ Organoleptic attribute } & \multicolumn{2}{|c|}{ Continuous scale } \\
\hline & & 0 & 7 \\
\hline Appearance & colour homogeneity & heterogeneous & homogeneous \\
\hline \multirow[t]{5}{*}{ Taste and odour } & creaminess & no detectable & intensive \\
\hline & dairy sour & slight & intensive \\
\hline & starchy taste & not detected & very intensive \\
\hline & astringent feeling & not detected & intensive \\
\hline & in the mouth & & \\
\hline \multirow[t]{2}{*}{ Consistency and texture } & softness & very soft & very firm \\
\hline & smoothness of mouth coating & slight & pronounced \\
\hline
\end{tabular}


served in glass plates. For organoleptic assessment the quantitative descriptive analysis was preferred (Murray et al., 2001; Stone and Sidel, 1993). Main attributes (Table 3 ) that can be affected by adding maltodextrin were chosen. Each attribute was rated on an increasing scale from 1 to 7 .

Statistical evaluation of the data. Data were processed by methods of mathematical statistics at confidence level 0.95. Statistical processing of data was carried out using computer programs Microsoft Office Excel 2010 and Mathcad 15.0.

\section{RESULTS AND DISCUSSION}

It was determined that an increase in the ratio of protein to total solids in UF milk resulted in a decrease in RFT and RCT. Results are presented in Table 4.

It was also shown in Table 2 that adding tapioca maltodextrin led to a decrease in RFT and RCT. The increased concentration of tapioca a maltodextrin does not affect the $\mathrm{pH}$-value of samples prepared for RFT and RCT determination.

This decrease in rennet coagulation time could be due to increase in rate of aggregation as a result of influence of tapioca maltodextrin on rennet enzyme.

Table 4. Effect of tapioca maltodextrin on rennet RFT and RCT

\begin{tabular}{lrrrrrr}
\hline & \multicolumn{5}{c}{ Samples } \\
\cline { 2 - 7 } Parameters & SM & UFC & UFTM 0.5\% & UFTM 1\% & UFTM 1.5\% & UFTM 2\% \\
\hline $\mathrm{pH}^{*}$ & 6.71 & 6.61 & 6.59 & 6.60 & 6.60 & 6.58 \\
RFT, s & 614 & 499 & 464 & 436 & 411 & 391 \\
$\mathrm{SD} * *$ & 19 & 17 & 14 & 13 & 14 & 11 \\
$\mathrm{RCT}, \mathrm{s}$ & 2400 & 2010 & 1860 & 1691 & 1499 & 1332 \\
$\mathrm{SD} * *$ & 101 & 75 & 62 & 51 & 55 & 60 \\
\hline
\end{tabular}

*Average of six replications.

**Standard deviation.

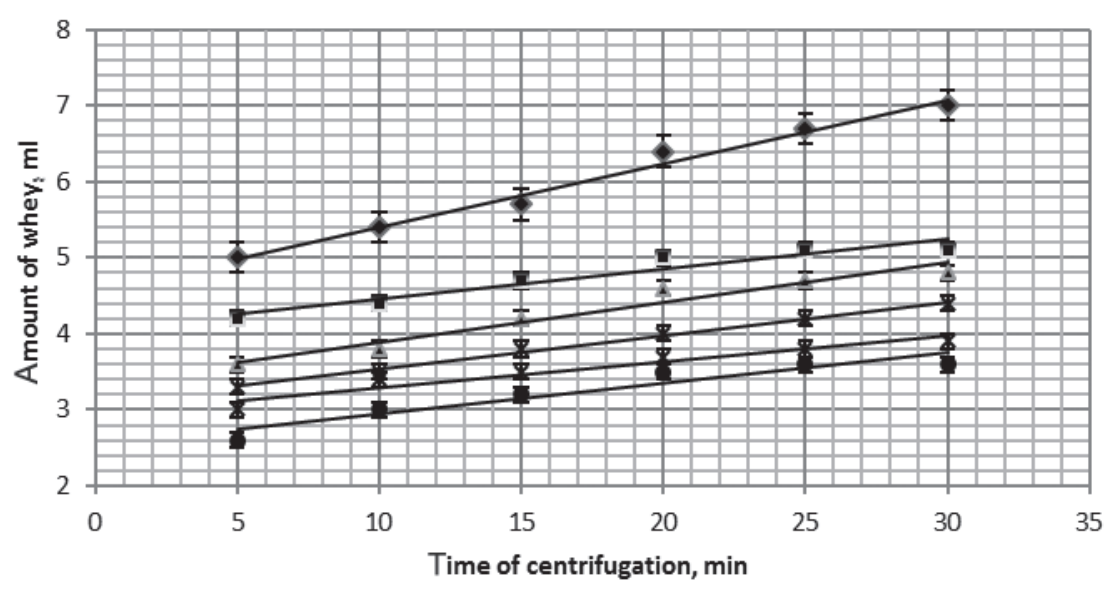

Fig. 2. Influence of maltodextrin concentration on moisture-binding capacity of

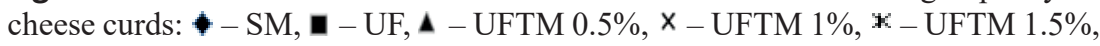
- - UFTM $2 \%$ 
Apparently, the addition of tapioca maltodextrin has activated the action of rennet enzyme and acted as a sort of glue that enables micelles to stick together upon collision.

As can be seen from Figure 2, the total solids increase in cheese curds made from UFC led to an increase in moisture-binding capacity in comparison with cheese curds made from unconcentrated SM. The increase of tapioca maltodextrin concentration also resulted in an increase of moisture-binding capacity in sample with adding maltodextrin tapioca as compared with the sample without the additive. It is can be caused by a decrease in volume of the aqueous phase using ultrafiltration and addition of tapioca maltodextrin to milk samples.

The results of the sensory assessment of soft cheese quality made from SM, UFC and UFC with different concentrations of tapioca maltodextrin are given in Figure 3. Cheese made from SM was chosen as a control sample.
Figure 3 presented that cheese made from UFC is more acceptable in terms of taste and odour, consistency and texture. The results showed that cheese made from UFC has a higher score for creaminess, firmness and smoothness of mouth coating. However, slight decrease of dairy sour taste was observed in comparison to cheese made from SM.

It can be seen that addition of tapioca maltodextrin influences the consistency and taste of soft cheese. The strongest evidence of a consistent effect was on creaminess intensity, smoothness of mouth coating. The increased amount of maltodextrin to $1.1 \%$ led to an increase of intensity of these attributes. The further increase led to the appearance of starch flavour and astringent feeling in the mouth that makes the product less acceptable for the consumer. Adding maltodextrin in different concentrations does not affect the colour homogenity of the product. The increase of

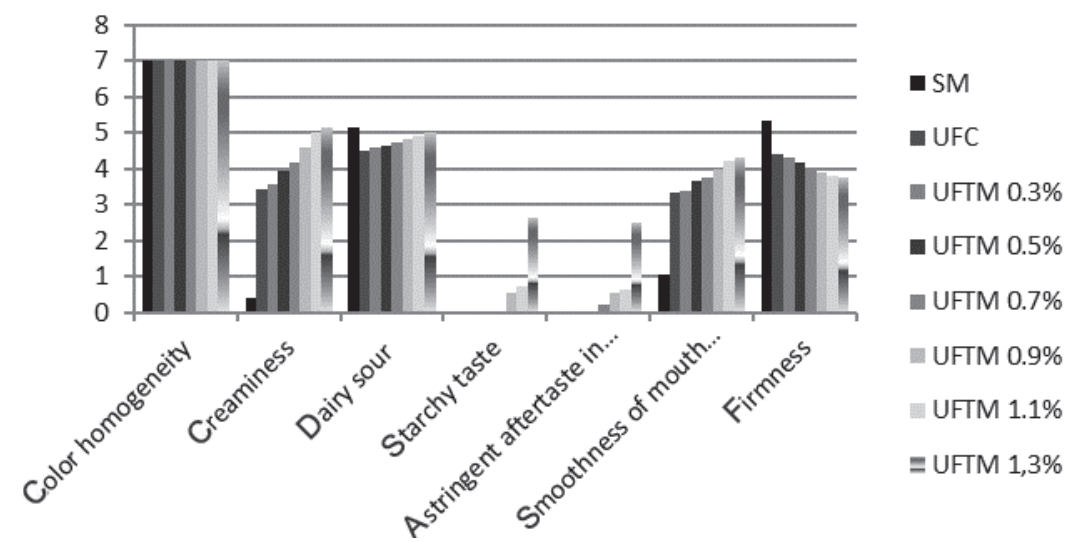

Fig. 3. Descriptive sensitive profiles for cheese samples made from SM, UFC and UFC with various concentrations of tapioca maltodextrin

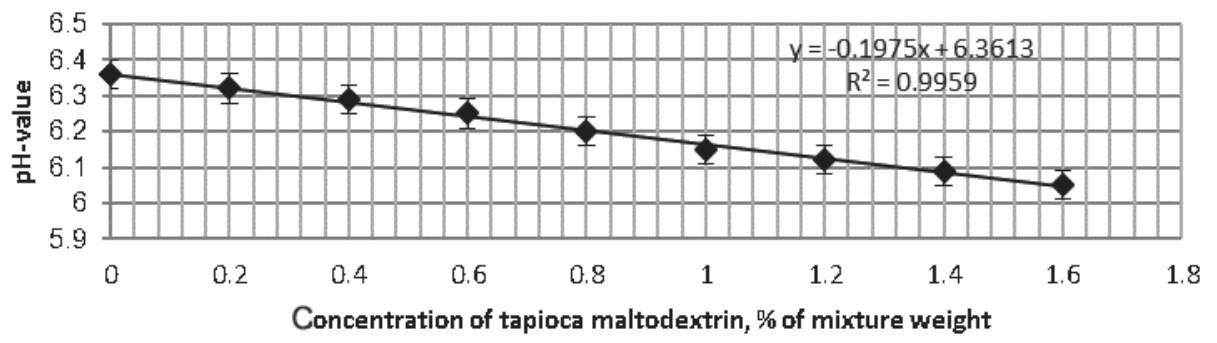

Fig. 4. Effect of tapioca maltodextrin concentrations on $\mathrm{pH}$-value of the soft cheeses 


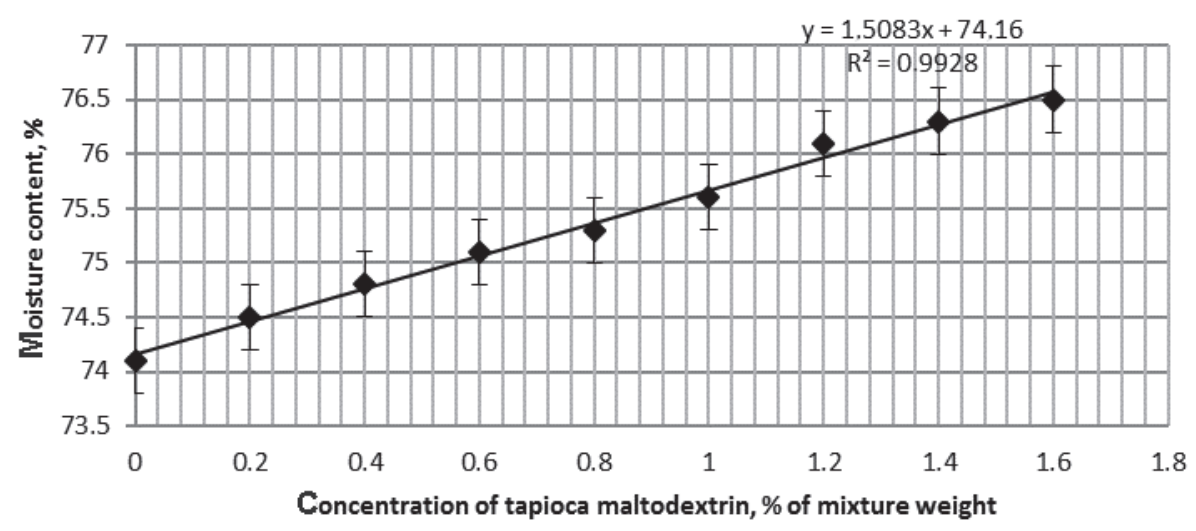

Fig. 5. Effect of tapioca maltodextrin concentration on moisture content of soft cheeses

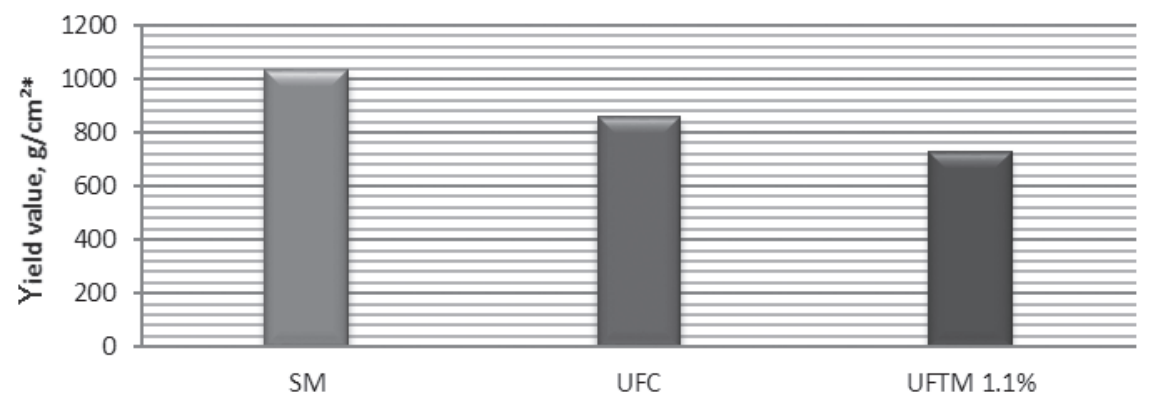

Fig. 6. Yield stress values of soft cheeses investigated: * - data performed an average meaning of three replicates

maltodextrin concentration led to a decrease of firmness of the finished product.

Based on the sensory characteristics of the soft cheese the addition of tapioca maltodextrin to the cheeses at level of $1.1 \%$ of mixture weight was preferred.

During the experiment the influence of concentration of maltodextrin tapioca on $\mathrm{pH}$-value were investigated. The data are presented in the Figure 4.

According to data obtained, $\mathrm{pH}$-value of cheeses made from UFC showed no significant difference with the use of different tapioca maltodextrin concentrations. Although, it had a tendency of a decrease $\mathrm{pH}$-value with the increase of the maltodextrin concentration. Apparently, it can be due to the bacteria, used as starter culture, ferment maltodextrin to produce lactic acid.

The results of the influence of tapioca maltodextrin on moisture content and rheological properties of cheeses are presented in Figure 5 and Figure 6.
Figure 5 showed that moisture content of soft cheeses was influenced by tapioca maltodextrin addition and increased with the increase of maltodextrin concentration. The comparison of consistency of soft cheeses made from SM, UFC and UFC with addition of tapioca maltodextrin in preferred concentration (UFTM $1.1 \%$; Fig. 6) showed differences in yield values.

According to Haighton's textural classification (Table 2) SM-sample can be referred to "too hard, limit of spreadability", UF-sample - "hard, but satisfactory spreadable", UFMD 1.1\%-sample - "plastic and spreadable".

These results related well to the results of sensory evaluation of soft cheeses, see Figure 3. Increased softness cheeses made with tapioca maltodextrin can be due to the maltodextrin creating discontinuities in the protein matrix and increased moisture level 
resulting from the high water binding capacity of the maltodextrin.

\section{CONCLUSIONS}

The results of the presented experiments showed a possibility of using tapioca maltodextrin in the manufacture of soft cheese. Studies carried out on soft cheese made using tapioca maltodextrin showed decreases in rennet flocculation time and rennet clotting time compared to skimmed milk soft cheese made without addition of maltodextrin. An addition of tapioca maltodextrin decreases to some extent the $\mathrm{pH}$-value of the finished product. The product had better moisture retention and showed less firmness, more creaminess and smoothness of mouth coating similar to the full fat soft cheese. Thus, the addition of maltodextrin appeared to improve the sensory characteristics of skimmed soft cheese. The recommended dose of the additive is $1.1 \%$ of mixture weight. Further increase of maltodextrin concentration led to the appearance of starchy taste and astringent aftertaste in the mouth. Hence, the addition of maltodextrin allows to some extent to solve the problem of dilute flavour, poor and rubbery consistency of the cheese made from skimmed milk.

\section{REFERENCES}

AOAC (1995). Official methods of analysis. Vol. II. 16th ed. Arlington: AOAC International.

AOAC (2000). Official methods of analysis international. 17th ed. Washington, DC: Association of Official Analytical Chemists.

AOAC (2002). Official methods of analysis. 17th ed. Gaithersburg, MD: AOAC.

Akoh, C. C. (1998). Fat replacers. Food Techn., 52, 3, 47-53.

Bhaskaracharya, R. K. (2004). Development of low fat and reduced fat mozzarella. A thesis submitted for the degree of doctor of philosophy. Australia, Victoria: Victoria University.

Clark, S., Costello, M., Drake, M., Bodyfelt, F. (2009). The sensory evaluation of dairy products. Springer Science + Business Media, LLC.

Drake, M. A., Boylston, T. D., Swanson, B. G. (1996). Fat mimetics in low-fat Cheddar cheese. J. Food Sci., 61, 6, $1267-1271$.
Erdem, Y. K. (2000). Influence of ultrafiltration on modification of surface hydrophobic sites of the milk protein system in the course of renneting. J. Food Eng., 44, 2, 63-70.

Fetisov, E. A., Chagarovskij, A. P. (1991). Membrane and molecular-sieve methods of treatment of milk. Moscow: Agropromizdat [in Russian].

Grandison, A. S., Glover, F. A. (1997). Membrane processing of milk. In R. K. Robinson (Ed.), Modern dairy technology. Vol. 1. Advances in milk processing. London: Chapman\&Hall, 273-311.

Haighton, A. J. (1959). The measurement of the hardness of margarines and fats with cone penetrometers. J. Am. Oil Chem. Soc., 36, 8, 345-348.

Hennelly, P. J., Dunne, P. G., O’Sullivan, M., O’Riordan, E. D. (2006). Textural, rheological and microstructural properties of imitation cheese containing inulin. J. Food Eng., 75, 3, 388-395.

ISO 8586-1:1993. Sensory analysis. General guidance for the selection, training and monitoring of assessors. Part 1. Selected assessors.

ISO 8589:2007. Sensory analysis - General guidance for the design of test rooms.

Kavas, G., Oysun, G., Kinik, O., Uysal, H. (2004). Effect of some fat replacers on chemical, physical and sensory attributes of low-fat white pickled cheese. Food Chem., $88,3,381-388$.

Kindstendt, P. (2005). American farmstead cheese. The complete guide to making and selling artisan cheeses. White River Junction: Chelsea Green Publ.

Koca, N., Metin, M. (2004). Textural, melting and sensory properties of low - fat fresh Kashar cheeses produced by using fat replacers. Int. Dairy J., 14, 4, 365-373.

Krupa, H., Jana Atanu, H., Patel, H. G. (2011). Synergy of dairy with non-dairy ingredients or product: A review. Afr. J. Food Sci.. 5, 16, 817-832.

Kuznetsova, L., Zabodalova, L., Baranenko, D. (2014). On the potential of lupin protein concentrate made by enzymatic hydrolysis of carbohydrates in dairy-like applications. Agron. Res., 12, 3, 727-736.

Lucey, J. (2000). Dairy ingredients in cheese making - possibilities and problems. Dairy Pipeline, 12, 2, 1, 4.

Murray, J. M., Delahunty, C. M., Baxter, I. A. (2001). Descriptive sensory analysis: past, present and future. Food Res. Int., 34, 6, 461-471.

Ohrimenko, O. V., Gorbatova, K. K., Ohrimenko, A. V. (2005). Laboratory practicum on chemistry and physics of milk. Saint-Petersburg: GIORD [in Russian].

Ong, L., Dagastine, R. R., Kentish, S. E., Gras, S. L. (2013). Microstructure and composition of full fat Cheddar 
cheese made with ultrafiltered milk retentate. Foods, 2, 3, 310-331.

Outinen, M. (2010). Effect of pre-treatment of cheese milk on the composition and characteristics of whey and whey products. Doctoral dissertation. Helsinki: Aalto University.

Pagliarini, E., Beatrice, N. (1994). Sensory and rheological properties of low-fat filled 'pasta filata' cheese. J. Dairy Res., 61, 2, 299-304.

Paulson, B. M., McMahon, D. J., Oberg, C. J. (1998). Influence of sodium chloride on appearance, functionality, and protein arrangements in nonfat Mozzarella cheese. J. Dairy Sci., 81, 8, 2053-2064.

Rebinder, P. A., Semenenko, N. N. (1949). About the method of cone penetration for characteristics of structural and mechanical properties of plastic - viscous bodies. Doklad. Akad. Nauk. SSSR, 64, 6, 835-838 [in Russian]. Sipahioglu, O., Alvarez V. B., Solano-Lopez C. (1999). Structure, physico-chemical and sensory properties of feta cheese made with tapioca starch and lecitin as fat mimetics. Int. Dairy J., 9, 11, 783-789.

Sommer, H. H., Matsen, H. (1935). The relation of mastitis to rennet coagulability and curd strength of milk. J. Dairy Sci., 18, 741-749.
Stone, H., Sidel, J. L. (1993). Sensory evaluation practices. California: Academic Press.

Vaclavik, V., Christian, E. (2008). Essentials of food science. Electronic text data. New York, NY: Springer Science + Business Media LLC. Retrieved from: http:// dx.doi.org/10.1007/978-0-387-69940-0.

WHO (2015). WHO Media centre. Cardiovascular diseases (CVDs). Fact sheet $\mathrm{N}^{\circ} 317$, updated January 2015. Geneva: World Health Organization. Retrieved from http:// www.who.int/entity/mediacentre/factsheets/fs317/en/-42k.

WHO (2015). WHO Media centre. Obesity and overweight. Fact sheet $\mathrm{N}^{\circ} 311$, updated January 2015. Geneva: World Health Organization. Retrieved from http://www.who. int/entity/mediacentre/factsheets/fs317/en/-40k.

WHO (2015). WHO Media centre. Diabetes. Fact sheet $N^{\circ} 312$, updated January 2015. Geneva: World Health Organization. Retrieved from http://www.who.int/entity/ mediacentre/factsheets/fs317/en/-38k.

Zalazar, C. A., Zalazar, C. S., Bernal, S., Bertola, N., Bevilacqua, A., Zaritzky, N. (2002). Effect of moisture level and fat replacer on physicochemical, rheological and sensory properties of low-fat soft cheeses. Int. Dairy J., $12,1,45-50$. 